\title{
Analysis of Governmental Environmental Responsibility System Based on Transaction Costs*
}

\author{
AiLijuan, Chen Junhong, Wang Ziyan, Du Chuntao \\ Department of Humanities and Social Sciences \\ Dalian University of Technology \\ China, Liaoning, Dalian, Ganjingzi District
}

\begin{abstract}
Governmental environmental responsibility system, as an important part of China's environmental governance system, plays an important role in fulfilling governmental environmental responsibility and promoting the construction of ecological civilization. This paper points out the problem of transaction costs in the governmental environmental responsibility system as a political contract, analyzes the performance and causes of the high transaction costs, puts forward to improve the environmental information disclosure, promotes the optimization and integration of environmental protection institutions and the integrity of the power and responsibility chain, implements the auditing system for the departure of environmental protection responsibilities of leading cadres, establishes grid seamless environmental supervision with public participation, and constructs multiple rights protection channels to reduce transaction costs, thereby further improving the government's environmental responsibility system.
\end{abstract}

Key words: Governmental environmental responsibility system; Transaction costs; Political contract

China has entered a new era of ecological civilization construction. In the "government-led" social environment, the governmental environmental responsibility system, as an important part of China's environmental governance system, plays an important role in fulfilling governmental environmental responsibility and promoting the construction of ecological civilization. From the perspective of transaction costs, this paper discusses the governmental environmental responsibility system as follows: what is the governmental environmental responsibility system? What are the transaction costs in the construction of governmental environmental responsibility system, and what are their forms and causes? What measures can be taken to reduce their transaction costs? This paper discusses and answers these questions, clarifies the types, manifestations and causes of transaction costs in the construction of governmental environmental responsibility system, and puts forward specific measures to reduce transaction costs.

1.Governmental environmental responsibility system and transaction costs

1.1Governmental environmental responsibility system

Since the reform and opening up, while China's economy has grown at a high speed, it has also caused serious environmental pollution problems due to the extensive development model ${ }^{[1]}$, especially in recent years, environmental problems such as haze and water pollution have occurred from time to time. This has not only become a bottleneck in China's economic development, but also seriously threatens the health of the people. Yale University's 2016 Environmental Performance Index Report shows that China ranks 109th out of 180 countries $^{[2]}$. Facing the severe environmental situation, the government, as the main body of environmental governance responsibility, is actively exploring the construction and implementation of governmental environmental responsibility system.

(1) Formation and development

Our government's environmental responsibility system has gone through a long process from brewing and budding to its formal establishment. The Human Environment Declaration issued by the United Nations Conference on the Human Environment in 1972 proposed "environmental right" as a new type of citizen's right ${ }^{[3]}$, and many countries have since

\footnotetext{
*Liaoning provincialsocial science planning fund "Theoretical construction and practical exploration of ecological welfare in the new era." (L19BJL004); National Natural Science Foundation of China, "Study on multi-source and trans-border ecological environment benefit compensation mechanism in Liaodong Bay." (No.71074024); Project funded by basic scientific research operating expenses of central universities: "Theoretical research on socialist ecological welfare with Chinese characteristics." (No : DUT18RW214); Dalian Social Science and Technology Federation Project: Exploration of Social Risk Governance in Large Public Project Operation(2019dlskyb006).

AiLijuan, Associate professor, Dalian university of technology, China, Email: ailijuan2010@ dlut.edu.cn; Chen Junhong, Postgraduate, Dalian university of technology, China, Email:827184499@qq.com; Wang Ziyan, Professor, Dalian university oftechnology, China, Email: 510715240@qq.com; Du Chuntao, Postgraduate, Dalian university of technology, China, Email: smiledudua@ mail.dlut.cn
} 
established it through legislation, and relevant environmental protection systems have also been launched. Our country also carries on the exploration practice unceasingly in this aspect:

In 1973, the First National Conference on Environmental Protection was convened and adopted Several Provisions on the Protection and Improvement of the Environment, representing the first step in China's environmental protection cause; In 1979, the eleventh session of the Standing Committee of the Fifth National People's Congress adopted the Environmental Protection Law of the People's Republic of China (Trial), which established the "three Simultaneities" system as a legal system; In 1989, the Third National Conference on Environmental Protection proposed eight systems of environmental management, including the responsibility system of environmental protection objectives; In 2001, the State Council promulgated the "Tenth Five Year Plan" for National Environmental Protection, in which the government is required to define environmental responsibilities and governance objectives with the responsibility goal of " reducing the total emission of major pollutants " ${ }^{[4]}$;In 2014, the newly revised Environmental Protection Law of the People's Republic of China emphasized the environmental responsibility of governments at all levels and established a strict responsibility system and assessment system for environmental protection target ${ }^{[5]}$; In 2015 , the newly revised Law of the People's Republic of China on the Prevention and Control of Atmospheric Pollution states that local governments are responsible for the quality of the local atmospheric environment ${ }^{[6]}$; In 2017, the newly revised Law of the People's Republic of China on Prevention and Control of Water Pollution takes the completion of water environment protection objectives as the content of assessment and evaluation of local governments and their principals ${ }^{[7]}$; With the continuous improvement of the legal system, the government's environmental responsibility system has gradually become a regular means of environmental protection.

At the same time, the supervision of governmental environmental responsibility tends to be strict. In 2015 , the Fourteenth Meeting of the Leading Group of the Central Committee for Comprehensively Deepening Reform adopted the Environmental Protection Supervision Plan (Trial) and Measures for Investigating the Responsibility of the Leading Cadres of the Party and Government for the Damage to the Ecological Environment (Trial) and other plans, which listed the environmental protection responsibility of the local Party committee and the government as the key supervision objects, and implemented the "Party and government accountability, dual responsibility for one post, accountability for negligence ${ }^{[8]}$ ". Since then, a nationwide central environmental inspection operation has been launched. In the two years from the end of 2015 to 2017, the central environmental protection supervision act covered 31 provinces across the country and held a total of 18,199 party and government leading cadres. The scope and intensity of its accountability pushed the government's environmental responsibility system to a small climax.

\section{(2) Connotation interpretation}

Commons believes the system aims to control individual actions with collective action ${ }^{[9]}$.North regards the system as a factor restricting political, economic, and social interactions. It can be said that the restrictive role is the key to the existence of the system ${ }^{[10]}$. The role of the government's environmental responsibility system is to restrict the government's power to achieve unity with environmental responsibility. Its essence is to realize the exchange of citizen support and government environmental commitment. The exchange of rights in the political market is the signing of a political contract, that is, a contract signed by one party with another party in the political field in order to obtain certain benefits $^{[11]}$. The conclusion of the contract means the generation of responsibility. The responsibility is derived from the contract, which is the proper meaning of the contract.

To sum up, the governmental environmental responsibility system can be regarded as a political contract, which contains multiple environmental responsibilities. According to the difference between contract and environmental responsibility, the government's environmental responsibility system is divided into three levels: the contract between the government and citizens, the contract within the government, and the contract between the government and other organizations. The contract between the government and citizens is to realize the exchange between the government's legal power and environmental commitments. At this time, the government has the responsibility to protect the public's environmental rights; The contract within the government refers to the contract between the central government and the local government, and the contract between the upper and lower levels at the same level of government. When the contracting party is the central government and local government, the government has the responsibility to ensure the exercise of environmental rights and perform environmental functions in accordance with laws and regulations. When the parties are superior and subordinate in the same government level, the government has the responsibility to implement the specific environmental work; In the current practice of environmental governance in China, the contract between the government and other organizations mainly refers to the contract between the local government and the enterprise. At this time, the government has the responsibility to guide and restrict the environmental behavior of the enterprise. The relationship between different levels of contracts and governmental environmental responsibility is shown in Figure 1. 


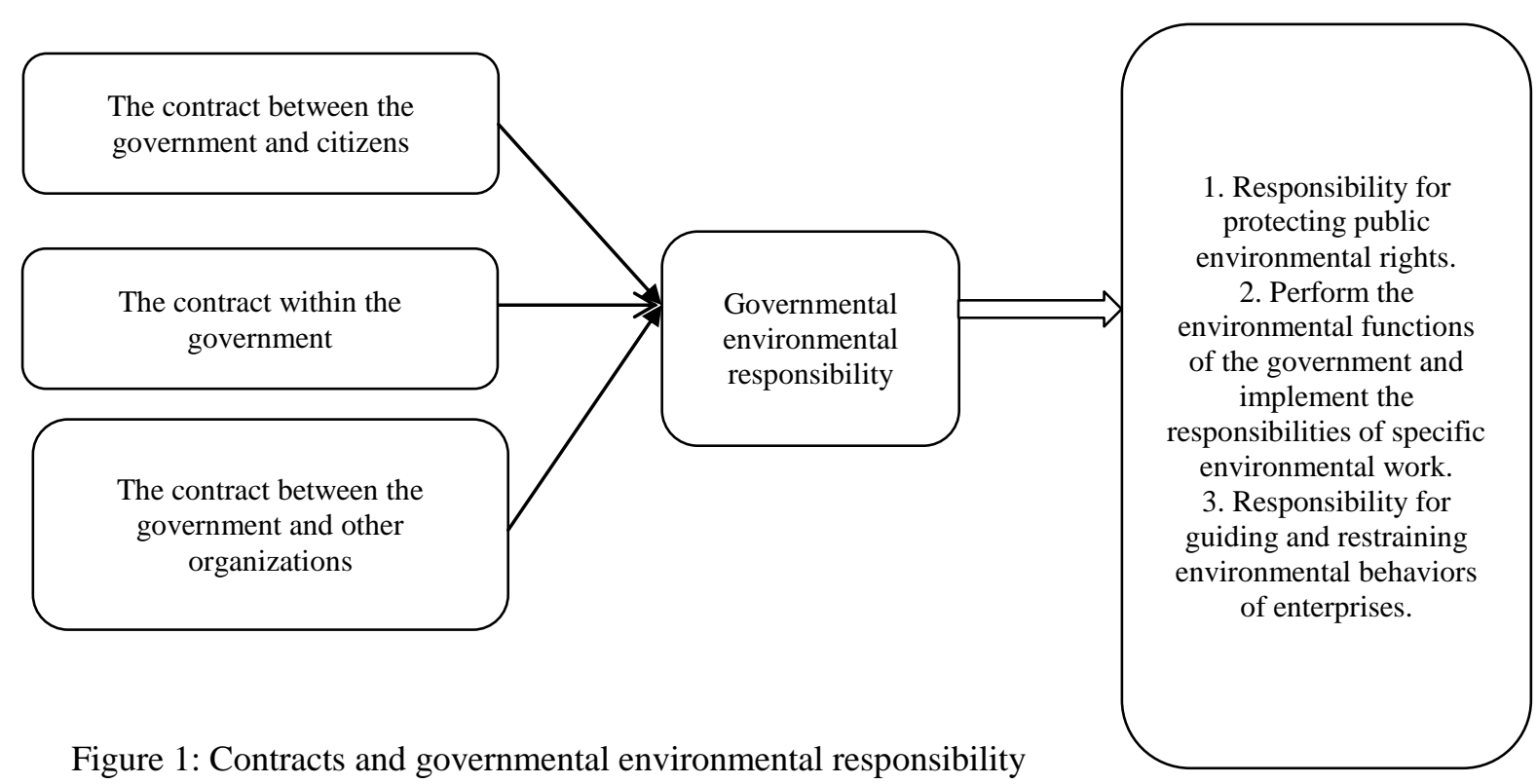

It is difficult to ensure that the government achieves the above-mentioned environmental responsibilities. Therefore, the target responsibility system, the assessment and evaluation system, the "military order" and other systems in the government's environmental responsibility system become the specific means to guarantee the realization of the government's environmental responsibility in the political contract. So it can be said that the governmental environmental responsibility system is a restriction mechanism to ensure the realization of the government's environmental responsibility in the political contract.

\subsection{Transaction costs of governmental environmental responsibility system}

To talk about the transaction costs in the system, we must first clear the transaction object and transaction method ${ }^{[12]}$. In the practice of environmental governance in China, there are three main types of transaction objects in the government's environmental responsibility system: government and citizens, lower and higher levels within the government (central and local governments, upper and lower levels of the same government level), and government and enterprises. Among them, the contract between government and citizens is the most fundamental political contract, which is the starting point and destination of all political contracts. The remaining two contracts are more specific contractual means in the governmental environmental responsibility system. In order to better realize the government's environmental commitment to citizens and realize the government's environmental responsibility, it is necessary to further improve the government's environmental responsibility system as a political contract, and the transaction costs is an effective tool to analyze the contract. So this paper discusses the government's environmental responsibility system from the perspective of transaction costs.

"Transaction costs" originated from Coase's The Nature of the Enterprise, which Arrow later described as "the costs of using the economic system" ${ }^{[13][25]}$. After that, the theory of transaction costs has been greatly enriched and developed by Williamson and other scholars, and has been widely used in the field of economics. At the same time, its strong explanatory power in the political field has also been found. In 1981, North used "transaction costs" to explain the institutional changes of the country ${ }^{[14]}$ and described the characteristics of political markets and the role of transaction costs in shaping political choices in political markets in the article Transaction costs Politics ${ }^{[15]}$, which marked the formal birth of transaction costs politics. There are different opinions on the definition of transaction costs in the political field. Foreign scholars often interpret it as "the comparative costs of planning, coordination and supervision to complete tasks under different governance structures" ${ }^{[16]}$, while Chinese scholars interpret it as various resources consumed by right exchange in the political field ${ }^{[11]}$. As mentioned above, the author regards the transaction costs of the governmental environmental responsibility system as various costs incurred in order to achieve governmental environmental responsibility in a political contract.

2.Analysis of transaction costs in governmental environmental responsibility system 2.1Types of transaction costs in the government's environmental responsibility system 
This paper draws on Delman's idea of conducting transaction costs research with the contract process as the main line, and divides the transaction costs in the government's environmental responsibility system into the transaction costs before the establishment of the system, the transaction costs when the system is established, and the transaction costs after the establishment of the system according to the order of occurrence of the phases.

(1) Transaction costs before the establishment of the government's environmental responsibility system

Environmental information costs is the main transaction costs before the establishment of the system. There are three types of environmental information in the government's environmental responsibility system: actual environmental conditions (actual information), environmental standards for measuring environmental quality (Information that should be), and expected environmental goals (the product of weighing discretion of the former two). The first type of environmental information acquisition requires the establishment of effective environmental monitoring networks and channels for environmental information disclosure; The second type of environmental information acquisition requires the use of environmental science research results and sound legal guarantees; The third type of environmental information acquisition requires the government to formulate environmental problem categories and determine expected environmental targets based on the first two types of information as indicators for evaluating environmental performance.The acquisition of all three types of environmental information requires a lot of costs. This part of environmental information costs is the main transaction costs before the establishment of the government's environmental responsibility system.

(2) Transaction costs in establishing governmental environmental responsibility system

(1) Decision costs. "It's hard for contract makers to predict the future, and it's hard for existing contract making technologies to combine the adaptability and accuracy of contracts" ${ }^{117]}$. Due to the existence of this incomplete contract, the decision-making results of the government in the process of establishing the system are uncertain. At the current technical level, the ability of environmental assessment and environmental prediction is also very limited, and the decision-making costs is inevitable.

(2) Organization costs. The establishment of the government's environmental responsibility system will inevitably have an impact on the existing government organizational structure and personnel, and then cause changes in the organization. The costs that the government must pay in order to respond to the organizational changes that occur.

(3) Sunk costs. In the process of establishing the government environmental system, the input or training costs of Party members and cadres must be paid and it is difficult to measure the benefits and costs, and the costs of talents for accountable officials is not profitable and difficult to recover, which forms the sunk costs.

(3) Transaction costs after the establishment of the government's environmental responsibility system

(1) Control costs. After the government's environmental responsibility system is established, in order to ensure the smooth implementation of the system, the government will adopt corresponding supervision and control methods and take punitive measures against the breaching party. The implementation of these measures requires a lot of manpower, material and financial resources to generate control costs that cannot be ignored.

(2) System operation costs. As a means of controlling and restricting government behavior, the operation of governmental environmental responsibility system needs the support of various supporting means, such as the perfection of relevant legal system, the publicity and popularization of relevant knowledge, etc., which is "the costs involved in the operation and adjustment of system framework in political system" ${ }^{,[18]}$.

(3)Rights protection costs. Protecting the public's environmental rights is the top priority of the government's environmental responsibility system.For the public whose rights have been damaged due to environmental problems, the government needs to help them directly or indirectly to obtain compensation, and the public who has not been compensated or insufficiently compensated needs to take measures to safeguard personal rights, such as petition, recourse to public interest litigation, etc., and these measures will costs a lot.

2.2 Transaction costs in governmental environmental responsibility system

(1) It is difficult for the superior government to obtain environmental information.

Compared with the developed countries in Europe and the United States, China's environmental standards are generally low. The formulation and implementation of environmental goals often lack effective communication between the upper and lower levels of the government, resulting in some local governments "responsible" without self-knowledge, and relevant environmental information can not be made public. At the same time, when the environmental standards are clear and the environmental objectives are clear, it is difficult for local governments to disclose all local environmental information. Only when the environmental problems are serious and cannot be concealed can environmental information be disclosed. The typical one is the ecological environment destruction event of Qilian Mountain National Nature Reserve in 2017. Due to local concealment, omission and other behaviors, the ecological environment destruction problem of Qilian mountain can not be solved. 
Until an academic paper is widely reprinted, the higher authorities pay attention to it and take strict control measures. And sometimes even if the superior asks the subordinate to make the information more public, the subordinate will refuse to provide the information for various "justified reasons" ${ }^{[19]}$,Therefore, the disclosure of environmental information in practice seems to be a form larger than content. Its true disclosure is very weak, and it is very difficult for the higher government to obtain environmental information.

(2) There are many obstacles to the concrete implementation of institutional reforms.

The vertical management reform of environmental protection institutions is of great significance to clarify the functions of the superior and the subordinate vertically. In 2016, the Ministry of Ecology and Environment issued the Guiding Opinions on the Pilot Work on the Reform of the Vertical Management System of Monitoring and Enforcement of Environmental Protection Institutions Below the Provincial Level to accelerate the vertical management reform of environmental protection institutions. However, the actual situation is as stated by the Minister of Ecology and Environment, Li Ganjie: The pilot work on the reform of the vertical management system for monitoring and enforcement of environmental protection agencies below the provincial level is progressing slowly. Institutional reforms in the field of environmental protection are entering deep-water areas, and reforms in the environmental protection "super-ministries system" have gradually begun. In 2018, the central government integrated a number of environmental protection responsibilities to establish the Ministry of Ecological Environment as an example. However, the institutional reform involves not only the adjustment of the affiliation of party members and cadres at lower or higher levels of the government, but also the redefinition and integration of the responsibilities among different levels, the functions of relevant departments, and the internal responsibilities of the environmental protection system. During the adjustment process, the immediate benefits such as the administrative status of some party members and cadres at lower levels may change. Once damaged, it is likely to adopt a delay or uncooperative attitude to slow down the implementation of the reform.

(3)It is difficult to implement the supporting "lifelong investigation system of responsibility for ecological environment damage".

The "Lifetime Accountability System for Ecological Environmental Damage Responsibility" was formally promoted in 2015 in the party and government leading cadres with the policies and regulations of Measures for Investigating the Responsibility for Ecological Environmental Damage of Leading Cadres of the Party and Government (Trial) ${ }^{[20]}$. At the same time, many local governments have issued relevant policy documents, but up to now, the lifelong accountability mechanism of ecological environmental damage in practice is still in the exploratory stage. In 2014, Wang Anshun, the former mayor of Beijing, signed a letter of responsibility with the central government to ensure that the annual concentration of fine particles in Beijing will be controlled at $60 \mu \mathrm{g} / \mathrm{m}^{3}$ by 2017, but in October 2016, Wang Anshun resigned as the mayor of Beijing and became the Secretary of the Party Group of the Development Research Center of the State Council. And the final environmental data in 2017 showed that the annual average concentration of PM2.5 in Beijing in 2016 was $73 \mu \mathrm{g} / \mathrm{m}^{3}$, which far exceeded the expected goal of the responsibility system. From the perspective of the contract, Wang Anshun did not complete the expected goals to achieve his environmental responsibility, and the central government should hold Wang Anshun accountable, but in practice, the "lifelong accountability system for ecological and environmental damage liability" has not been implemented.

(4) High costs of environmental accountability with the focus on central environmental supervision and frequent pollution rebound.

Environmental accountability is an important monitoring and control method of the government's environmental responsibility system. With the continuous advancement of the government's environmental responsibility system, environmental accountability has been strictly enforced by the central government, which is specifically reflected in the two-year central environmental protection inspection operation that began in late 2015. The main members of the central environmental protection supervision action include the staff of the Ministry of Ecological Environment, the staff of environmental protection institutions from other places and journalists. The whole supervision process includes three stages: talking with local leaders, on-site supervision and feedback. The supervision scope is wide, the personnel composition is complex and the supervision time is long, so it will costs a lot of manpower and time costs. Once this round of environmental protection supervision is over, the phenomenon of pollution rebound will occur. For example, some cities in Jiangxi have false rectification and perfunctory rectification, which leads to the problem of pollution rebound. At present, the action of "looking back" initiated by the central environmental supervision is an auxiliary control means to curb the phenomenon of pollution rebound, but it is also accompanied by the problem of high costs.

(5) Difficulties in safeguarding public environmental rights 
In the field of environment, there are two ways for the public to protect their environment rights: environmental public interest litigation and group action. Due to the particularity of environmental pollution, the causal relationship between the polluter and the victim is difficult to identify, and it is difficult to provide evidence. The environmental public interest litigation brought by ENGO as the public representative often fails. After losing the case of "Changzhou toxic land" public interest litigation, the "China Green Development Association" has to bear 1.89 million yuan of "sky high litigation costs". When the legalized expression channels are incomplete and the public environmental demands cannot be responded to, the public will be forced to take group actions, such as "sit-in" and "street trouble". In recent years, the group events of environmental protection rights have been increasing at an average annual rate of $29 \%{ }^{[21]}$. In the group action, the contradiction is easy to be intensified, which leads to the deterioration of the situation and even turns into violent conflict. This is the case for the group event of farmers protesting against environmental pollution in Dongyang city Huashui town. Finally, the government has to use the police and other forced ways to "maintain stability".The costs of protecting public's rights is huge, and the road of protecting environmental rights is very difficult, which makes the public's environmental rights not guaranteed.

2.3 Reasons for excessive transaction costs in the government's environmental responsibility system

Aiming at the government's environmental responsibility system, this article discusses the reasons for the high transaction costs from the administrative practice in China.

(1) Complexity and uncertainty of environmental problems

China is in a period of overlap and transition in which traditional and new types of environmental pollution coexist. Due to the complexity and uncertainty of environmental problems, decision makers have difficulty in calculating and comparing all environmental contracts, so bounded rationality must exist. The existence of bounded rationality causes systematic distortions in human understanding or thinking, so the costs of obtaining and processing information is very high $^{[22]}$. At the same time, people will develop cognitive biases, which will lead to decision errors ${ }^{[23]}$, and mistakes in decision making will incur huge decision costs. In political practice, it is difficult to formulate a perfect contract, because the limited rationality of decision makers will affect the readjustment of the organization and the implementation of the system. Therefore, in the implementation of the government's environmental responsibility system, the complexity and uncertainty of environmental problems are important reasons for transaction costs.

(2) Environmental information asymmetry

Environmental information asymmetry is an important inducement of opportunism, which refers to "incomplete or distorted disclosure of information, especially intentional acts that mislead, distort, cover up, confuse, or confuse information" ${ }^{[13]}$. For the purpose of maximizing their own benefits, subordinate governments and enterprises and institutions will use their own advantages to conceal or distort the local environmental information, which will seriously affect the identification and judgment of environmental issues by superior governments. At the same time, the environmental information asymmetry will also cause the post opportunistic behavior- moral hazard. It is also the behavior that uses the information advantage to take the opportunistic behavior and brings loss to the other party of the contract $^{[24]}$, for example, in the implementation of the government's environmental responsibility system, subordinates take advantage of the more complete information advantage of mastering environmental information, and reduce the risk of being held accountable through inaction or slow action.

(3)The boundary between power and responsibility in the field of environment is unclear, and it is difficult to attribute environmental problems to responsibility

The latent time of environmental problems is long, the causal chain is complex, and it is not easy to be found in a short time, such as river pollution, and its governance cycle is also long, such as the governance of haze. Due to the tenure system, local governments are more willing to give priority to the economic objectives, which have strong explicit performance. Environmental problems are ignored to some extent because they are hard to find in a short period of time. After the end of the term of office, the environmental problems and their governance in the future will become the responsibility of the next or several officials, so it is difficult to clearly define the boundary of power and responsibility in the field of environment. Correspondingly, the attribution and blame of environmental problems become very difficult. Due to the difficulty of attribution, it is easy for enterprises to discharge sewage and the public is difficult to defend their rights, and the difficulty of imputation makes it possible for current officials to be the object of prevarication. All these have led officials and enterprises to adopt an opportunistic approach when dealing with environmental issues.

(4)Over dependence on government led top-down control mode

For a long time, regulatory system of our country mainly relies on the government led, top-down control mode, as well as in the field of environment. 
At present, our country is vigorously implementing the strict supervision and control mode - the central environmental protection supervision action is also carried out in a government led, top-down way, but this supervision mode will costs a lot of human and time costs, resulting in a sharp increase in government control costs. At the same time, in the process of environmental supervision, it is necessary to allocate and integrate personnel, which will also increase the costs of the organization. The current environmental supervision relies too much on the government led top-down control mode and lacks diversified supervision methods, which makes the supervision unable to maintain continuity and requires constant "looking back", thus increasing the control costs of the government. Therefore, the excessive dependence on the government led top-down environmental supervision is one of the reasons for the high transaction costs in the governmental environmental responsibility system.

3. The construction path of governmental environmental responsibility system based on transaction costs.

Based on the above analysis, we can see that there are excessive transaction costs in the promotion of the government's environmental responsibility system, but the existence of the system itself will generate transaction costs ${ }^{[25]}$. Therefore, the transaction costs in the government's environmental responsibility system is inevitable, but we can still take measures to reduce it to a certain extent. Starting from the perspective of transaction costs, we can construct and improve the government's environmental responsibility system from the following aspects.

\subsection{Further improve environmental information disclosure}

Establishing a green channel for environmental information, strengthening pre-environmental monitoring of the environment, and further improving the disclosure of environmental information are important ways to reduce the costs of environmental information and thereby reduce the transaction costs of the government's environmental responsibility system. As the responsible body, it is necessary for the government to disclose environmental information. The central government should establish a green channel for environmental information for the public and local governments, create opportunities for the public that are different from reporting and petitioning for environmental information, and provide local governments with a new way of environmental information disclosure that is different from disclosure based on applications and voluntary disclosure. The government is committed to the timely processing of all environmental information in the green channel of environmental information, strict accountability for false environmental information, and serious treatment of real environmental information. At the same time, it is necessary to strengthen environmental pre supervision, use scientific and technological supervision means such as environmental supervision network in parallel with field supervision, strengthen environmental supervision, make environmental pre supervision become an auxiliary means to collect environmental information and formulate environmental standards, and normalize and institutionalize environmental pre supervision.

3.2Promote the optimization and integration of environmental protection institutions and the integrity of the power and responsibility chain

The implementation of "environmental power list" and "environmental responsibility list" within the department, the optimization and integration of environmental protection institutions and the integrity of the power and responsibility chain play an important role in reducing the organizational costs and the transaction costs in the government's environmental responsibility system. Under the background of "large-scale reform", it is very important to realize the rapid and efficient establishment of large departments of environmental protection institutions, and the implementation of "environmental power list" and "environmental responsibility list" within departments is an effective way to improve organizational efficiency and reduce organizational costs. Under the premise of full coverage of responsibilities, clearly divide the power and responsibility boundaries of environmental protection agencies, implement the "environmental power list" and "environmental responsibility list" within the department, detail what each agency can and cannot do and what to do, and the corresponding responsibilities for certain important environmental policies or environmental decisions should be implemented to specific departments or even individuals rather than the current general responsible agencies such as the "Municipal Environmental Protection Bureau" and "Municipal Development and Reform Commission". In addition, to prevent the occurrence of responsibility vacuum or responsibility cracks, and avoid the possibility of mutual prevarication between departments, so as to form an overall organizational structure of coordination between superiors and subordinates and orderly linkage between departments, and promote the optimization and integration of environmental institutions and the integrity of the environmental rights and responsibilities chain.

\subsection{Implementation of the "Leadership Audit System for Leading Cadres for Environmental Protection}

In the case of unsatisfactory implementation of "lifelong investigation system of responsibility for ecological environment damage", it is an effective way to reduce sunk costs and organizational control costs to implement and improve "audit system of environmental protection responsibility of leading cadres". 
During the term of office or at the end of the term of office of the leading cadres, as long as any cadres leave office, they should be audited and evaluated for their environmental protection responsibilities. Only leading cadres with good evaluation results can leave the office normally, otherwise they must be held accountable in accordance with the law, which can effectively prevent the situation of signing new contracts with superiors after the cadres who are to be held responsible leave, thereby reducing the sunk costs. At the same time, the audit system for the departure of environmental protection responsibility of leading cadres can reduce the opportunistic psychology of leading cadres, avoid the practice of using the departure to evade environmental responsibility, and thus reduce the control costs of the government. Therefore, the implementation of the audit system for the departure of environmental protection responsibility of leading cadres plays an important role in reducing the transaction costs of the government's environmental responsibility system.

\subsection{Establish seamless grid environment supervision with effective public participation}

The current environmental accountability supervision mode, represented by the central environmental supervision, is more suitable for special periods due to its high costs, such as the early stage of ecological civilization construction we are now in. Therefore, in the long run, it is an effective way to reduce the control costs to establish seamless grid environment supervision with effective public participation. "Grid environmental supervision" is a new type of environmental supervision mode tried out by local governments in our country, but most of it is limited to the supervision of all levels of government organizations. At the same time of government supervision, the effective participation of the public will be included in it to form seamless grid environment supervision, so that the public can realize the supervision of the government through the regular supervision track, thereby achieving standardization and normalization of public supervision. At the same time, once the officials realize the existence of this seamless supervision, they will be more careful to implement various arrangements under the system, which is more conducive to reducing the control costs of the government, so this is a very effective way to reduce the transaction costs in the construction of the governmental environmental responsibility system.

\subsection{Establish diversified channels of environmental rights protection and environmental funds}

Establishing multiple channels for environmental rights protection, allowing the public to express environmental demands through formal means, and encouraging the industry to establish environmental funds, so that the public who have suffered damage to environmental rights are compensated in a timely manner are effective ways to reduce the costs of rights protection. To build multiple channels for safeguarding rights and change the thinking habit of "noisy" in public environmental protection, especially to add ways of safeguarding rights for special groups. For example, the adjustment of the local village officials and cadres should be the focus of the farmers, so that the rights protection can be carried out in a way that they can understand, and realize the rights protection at the basic level. Although in the process of achieving ecological governance, the development of cleaner production technologies is the radical way for high-polluting industries, but encouraging chemical industry and other industries to establish environmental funds through government support and other methods still plays an important role in protecting their right Enterprises in the industry pay part of the annual fund fee in proportion. The main fund fee come from polluted enterprises that are held accountable in the government's environmental responsibility system. For the public whose physical and mental health has been damaged by pollution in related industries, the costs of treatment and compensation is also paid by the fund to ensure that all damaged public can get reasonable compensation.

To sum up, our government's environmental responsibility system is still in its infancy and development stage, and the system's flexibility and adjustability are still very strong. Therefore, in the process of exploring practice, continuously reducing transaction costs through effective institutional innovation approaches is of great significance for improving the existing governmental environmental responsibility system.

\section{References}

Wang Min, Huang Yan. Environmental Pollution and Economic Growth in China [J]. Economics: Quarterly, 2015 (1): 557-578.

Yale Center for Environmental Law and Policy, International Earth Science Information Network(CIESIN).Global metrics for the environment: The Environmental Performance Index ranks countries' performance on highpriority environmental issues.[R/OL]. (2016-01-28)[2018-4-20].http://epi.yale.edu.

Zhu Guohua. Research on governmental environmental responsibility in environmental governance in China. Nanchang University, 2016

Wang Xinfang. Explanation on the "Tenth Five-Year Plan" for National Environmental Protection . Environmental Protection, 2002 (3): 10-13. 
Chen Haisong. The implementation path of government's environmental responsibility in the new environmental protection law -- An Investigation Centered on the responsibility system of environmental protection objectives and the assessment and evaluation system. Social scientist, 2017 (8): 14-19

Ministry of Ecology and Environment of the People's Republic of China.Law on the Prevention and Control of Air Pollution of the People's Republic of China (President Order No. 31) [EB / OL].(2015-09-06) [2018-4-20].

http://www.mep.gov.cn/gzfw_13107/zcfg/fl/201605/t20160522_343394.shtml?COLLCC=257870106\&.

Ministry of ecology and environment of the people's Republic of China. Law of the people's Republic of China on prevention and control of water pollution [EB / OL] (January 1, 2018) [April 20, 2018]

http://www.mep.gov.cn/gzfw_13107/zcfg/fl/201803/t20180309_432235.shtml?COLLCC=257828347\&.

Zhang Gaoli, central environmental protection supervision [J], environmental protection, 2016 (24): 10-10

Commons, translated by Yu Shusheng.Institutional Economics (Part I) [M]. Beijing: Commercial Press, 1997: 89

DouglassC.North.Institutions[J]. Journal of Economic Perspectives, 1991,5(1):97-112.

Huang Xinhua. Economic Analysis of Political Transaction_-A Review of Contemporary Western Transaction costs Politics. Journal of Xiamen University (Philosophy and Social Sciences), 2009 (5): 5-13.

CaiChangkun. From "huge government" to "smart government": the logic of China's government function transformation -- from the perspective of transaction costs politics. Public administration review, 2015 (2): 99124

Michael Dicky. Economics of Transaction Costs.Translated by Wang Tiesheng, GeLicheng. Beijing: Economic Science Press, 1999.

Douglas C. North. Structure and Changes in Economic History.Translated by Chen Yu, et al. Shanghai: Shanghai Sanlian Bookstore, Shanghai People's Publishing House, 1991.

North D C. A Transaction costs Theory of Politics. Journal of Theoretical Politics, 1990, 2(4): 355-367.

Avinash K. Dixit. Formulation of Economic Policy: A Perspective of Transaction costs Politics. Liu Yuanchun, Trans. Beijing: China People's University Press, 2004: 22.

Oliver E. Williamson. Transaction-Costs Economics: The Governance of Contractual Relations[C]// Journal of Law \& Economics. 1979:233-61

Eric Fruboton, Rudolph Richett: New Institutional Economics: A Paradigm of Transaction costs Analysis, Shanghai: Shanghai Sanlian Bookstore, Shanghai People's Publishing House, 2006, p. 61.

Fan Liangshu. Research on the solution path of "Chinese style dilemma" of environmental rights protection. Social Sciences, 2015 (5): 50-53

Wang Jingbo, Li Shuai. Problems, Countermeasures and Prospects of the Government Information Publicity in China. Administrative law research, 2017 (2)

General Office of the Central Committee of the Communist Party of China. Measures for investigating the responsibility of leading cadres of the party and government for ecological environment damage (Trial) [J]. Gansu Forestry, 2015 (6): 14-15

FengZhongyue, Zhang Xiufen. Internality, Multiple Moral Hazard and Safety Regulation:_—Based on the Perspective of In group. Jinyang journal, 2017 (3): 132-139

Zhou ye'an. Behavioral economics: leading the future of Economics. Southern economy, 2018 (2)

K Scott,“ Bounded Rationality and Social Norms: Concluding Comment”, Journal ofInstitutional and Theoretical Economics,150(1994).p.315-319.

Zhang Wuchang. Paradigm of transaction costs. Social science front, 1999 (1): 1-9 